\title{
A atuação internacional do Estado em benefício de interesses privados: uma análise jurídica da formação da "micropolítica" externa
}

\section{HENRIQUE CHOER MORAES*}

\section{Introdução: em busca do interesse nacional na política comercial externa}

Há cinqüenta anos, Charles Wilson expunha ao Armed Services Committee do Senado norte-americano sua visão da política externa: “o que é bom para a General Motors, é bom para o país.”1

A condução da política externa de um Estado implica perseguir, no cenário das relações internacionais, o interesse nacional. Dentro de uma democracia, o termo deve significar mais que um argumento de retórica política e traduzir-se em mecanismos institucionalizados de diálogo entre o governo e os setores da sociedade que têm interesse nos mais variados campos de atuação externa do Estado. Desse modo, fica claro que, a par da dificuldade da defesa do interesse nacional (que é externa, no sentido de que trava relações com outros atores internacionais), o comportamento externo pressupõe o diálogo interno no qual é definido, concretamente, o que abrange o interesse nacional ${ }^{2}$.

Sob a perspectiva da teoria liberal das relações internacionais, o Estado age como representante de interesses de setores da sociedade que têm acesso às instâncias decisórias que determinam, concretamente, o alcance do interesse nacional $^{3}$. Nesse sentido, a própria idéia de interesse nacional é desvirtuada, autorizando Stephen KRASNER a sustentar que, na teoria liberal, "the concept of public interest slips away" na medida em que "from a liberal perspective, the public or national interest can only mean some summation of private interests" 4 .

Desse modo, a importância da transparência que decorre da institucionalização do diálogo Estado-sociedade repousa sobre esse ponto - a busca em propiciar o mais amplo diálogo possível - de modo a evitar a "feudalização” da condução da política externa e, ao contrário, permitir o mais amplo acesso à sua formação ${ }^{5}$. 
O incremento da legalização dos regimes internacionais ${ }^{6}$ de comércio coloca na pauta das discussões a forma como um Estado elabora a sua política comercial externa, justamente porque as normas internacionais produzem, de maneira crescente, efeitos domésticos ${ }^{7}$. Com efeito, as negociações de abertura de mercados transformaram as burocracias estatais em defensoras dos interesses de suas economias domésticas.

O advento da Organização Mundial do Comércio (OMC), com os órgãos e procedimentos técnicos que criou, ilustra exemplarmente essa atuação da diplomacia econômica que fez com que os Estados tivessem de voltar-se para a discussão no nível técnico (econômico e jurídico) ${ }^{8}$, na medida em que a discussão política diminuía seu impacto, sem deixar, contudo, de estar presente.

Analisada juridicamente, a Rodada Uruguai atribuiu uma série de novos deveres aos Estados que então ingressavam na OMC (no sentido do aumento tanto do free quanto do fair trade), ao mesmo tempo em que franqueava aos agentes do comércio internacional - particulares, na maioria dos casos - "direitos" de acesso aos mercados estrangeiros. Eis, em síntese apertada, a "fenomenologia” das normas decorrentes dos acordos da OMC: Estados obrigando-se a garantir melhor acesso aos seus mercados, o que corresponde, inegavelmente, a benefícios criados para particulares ${ }^{9}$.

O argumento pode ser visto, sob uma ótica mais ampla, como um exemplo da estrutura do próprio International Trade Law, considerado como um conjunto de regras de Direito Internacional (porque criadas entre Estados ${ }^{10}$ ), visando liberalizar o comércio internacional por meio da redução das atividades estatais que, de alguma forma, obstaculizam ou prejudicam o comércio leal. Como as operações de comércio internacional são protagonizadas por particulares, são estes os principais sujeitos beneficiados pelas normas, ao passo que são os Estados os sujeitos passivos das obrigações.

O aumento do fluxo comercial internacional atribuído a esse movimento de abertura de mercados projeta a concorrência comercial definitivamente para a escala internacional e uma série de agentes privados desponta como atores das relações internacionais.

Porém, a despeito da aparente “auto-suficiência” dos agentes particulares para competir no cenário internacional, uma vez que os mercados ficam mais acessíveis, a institucionalização do Direito Internacional do Comércio não acompanhou o ganho de complexidade das relações internacionais e as empresas ainda mantêm-se atadas aos seus Estados; é imprescindível a atuação externa do Estado em seu benefício.

E aqui está o objetivo do presente trabalho: mostrar que, apesar da "globalização" dos mercados, as empresas ainda precisam de seus Estados para a defesa dos seus interesses perante a maior parte das instâncias internacionais. Em outras palavras, o exame seguinte procura mostrar por que as empresas, por um 
lado, são atores das relações internacionais, mas, por outro, ainda não sujeitos de Direito Internacional.

Assentada essa premissa, demonstrada adiante, pode-se entender por que, em Direito Internacional do Comércio, a atuação externa do Estado é pautada por um "interesse nacional” que se confunde com aquele das empresas interessadas na solução de um determinado problema; a idéia é que seja a resultante da "mediação" de todos os interesses dos setores atingidos. Assim, para compreender como se atualiza esse "interesse nacional” impõe-se empreender um exame dos meios institucionalizados de diálogo entre setores interessados da sociedade e o governo, o que possibilita avaliar as vias de acesso ao Estado e, em parte, compreender o seu processo decisório.

As decisões dos Estados que digam respeito à defesa internacional do interesse de sua indústria doméstica são, definitivamente, decisões de política externa. No entanto, reconhecendo o alcance da decisão, convém adotar um neologismo - a "micropolítica” externa - para destacar o caráter tópico dessa espécie de decisão, que se oporia às demais decisões de política externa, aquelas nas quais as principais linhas de ação internacional do Estado são estabelecidas e que, portanto, têm abrangência maior.

Segue, em suma, uma análise que tenta responder: quais as normas que regulam o contato de um particular ao seu Estado para que defenda interesse seu? Qual margem de decisão possui o Estado para dar prosseguimento internacional à queixa de sua indústria? Como os setores da sociedade interessados participam desse processo decisório? Uma perspectiva jurídica dessas questões deverá ser capaz de mostrar como o diálogo entre o governo brasileiro e a sociedade é pouco institucionalizado.

\section{Delimitação do exame}

O estudo ocupa-se em mostrar a formulação da "micropolítica” externa em dois de seus momentos, ambos inseridos no contexto do Mecanismo de Solução de Controvérsias (MSC) ${ }^{11}$ da OMC: (a) a provocação da atuação do Órgão de Solução de Controvérsias (OSC) e dos órgãos técnicos que lhe são subordinados (os painéis e o Órgão de Apelação); e, (b) o descumprimento, por parte do Estado perdedor em uma controvérsia, das decisões emanadas do OSC.

Vistos sob a perspectiva dos particulares interessados, os dois tópicos traduzem-se nos dois capítulos em que se divide o exame, que privilegia o diálogo - que se trava no plano interno - entre o Estado e setores da sociedade. Assim, cuida-se de compreender como, no Brasil, a queixa de um particular chega até ao OSC (I) e, em um segundo momento, demonstrar quais os efeitos que a indústria nacional pode sofrer com o eventual descumprimento pelo Brasil de uma decisão emanada do OSC (II). 


\section{O acesso da queixa da indústria doméstica à OMC}

Como assinalado, as normas da OMC atribuem deveres a Estados e criam correlativos benefícios a particulares. Juridicamente, porém, os particulares beneficiados por tais normas não podem reivindicar na Organização a punição do Estado que eventualmente tenha reduzido ou retirado algum benefício.

Um dos principais requisitos para que se possa atribuir a personalidade jurídica internacional é que o beneficiário da norma possa reclamar contra a sua violação em foro internacional ${ }^{12}$. Assim, não basta que a norma, em sua redação, atribua "direitos" a alguém; é preciso que, igualmente, confira o direito de pleitear, perante tribunais internacionais, contra a violação desses direitos. Isso não é o que sucede com os particulares na OMC.

Com efeito, as normas da OMC não apenas foram negociadas pelos Estados, como também serão fiscalizadas por eles, a partir sobretudo da provocação da atuação do MSC, cujo acesso (locus standi) lhes é restrito; ou seja, os particulares não possuem titularidade para colocar em marcha o procedimento do $\mathrm{MSC}^{13}$.

Desse modo, por exemplo, o prejuízo que um setor da indústria brasileira sofre com o comportamento infrator de um Membro da OMC deve ser encaminhado ao governo brasileiro para que este, então, conduza a reclamação ao OSC; isso implica dizer que, se o governo brasileiro entender que não há conveniência política em encaminhar a queixa à OMC, o prejuízo da indústria doméstica não é reparado. Estamos, portanto, diante do instituto jurídico da proteção diplomática ${ }^{14}$.

A proteção diplomática, clássica figura do Direito Internacional, decorre da ficção, consagrada em normas jurídicas, de que a "sociedade internacional” é composta apenas por Estados, e que estes servem de mediadores entre seus nacionais e os demais Estados. Cuida-se, na verdade, de regra procedimental que serve para explicar como as queixas dos nacionais de um Estado podem ser opostas contra outro: sempre através do Estado nacional.

A Comissão de Direito Internacional da ONU tem se debruçado sobre o tema desde 1996 e, em seu Relatório acerca da matéria, define a relação existente na proteção diplomática da seguinte forma: "In the present articles diplomatic protection means action taken by a State against another State in respect of an injury to the person or property of a national caused by an internationally wrongful act or omission attributable to the latter State."15

Ainda uma outra ficção sustenta a idéia da proteção diplomática: a ficção de que o prejuízo causado por um Estado a um estrangeiro é, ao mesmo tempo, um dano causado ao Estado do qual o estrangeiro é nacional. Em virtude dessa ficção, o prejuízo ensejado ao particular ganha dimensão internacional porque coloca dois Estados a ocupar nos pólos da controvérsia ${ }^{16}$.

O Direito Internacional condiciona o exercício da proteção diplomática à observância de dois requisitos: primeiramente, a nacionalidade do reclamante deve 
ser, em regra, a do Estado que propõe internacionalmente a queixa; em segundo lugar, o particular deve demonstrar ao Estado nacional ter esgotado os recursos internos que o Estado infrator lhe proporcionara para, autonomamente, reclamar. Só então o Estado nacional pode lançar-se contra o outro Estado.

Espaço que não é ocupado pelo Direito Internacional, contudo, é o do diálogo entre o particular lesado e o Estado nacional. Esse espaço é preenchido pelo direito interno de cada Estado, que pode determinar não apenas as formas pelas quais o particular acessa o Estado - para apresentar sua queixa, mas também o âmbito de decisão que o governo detém para endossar ou não a queixa.

E é nesse segundo ponto que radica a principal desvantagem das ficções que sustentam o instituto da proteção diplomática: a decisão do Estado nacional de amparar a queixa do particular é política, o que pode fazer com que os prejuízos fiquem desamparados por conta dos cálculos de conveniência que podem demonstrar ser politicamente custosa a controvérsia vis-à-vis o Estado infrator.

Eis um espaço atribuído à discricionariedade do Poder Executivo: apesar de ser beneficiado pela norma jurídica, o indivíduo, pode-se dizer, não é titular de direito subjetivo dele decorrente, na medida em que não pode fazê-la valer ${ }^{17}$ autonomamente nos casos de violação. A proteção diplomática, assim, sinaliza a descentralização da sociedade internacional; ao consagrar juridicamente a ficção de que apenas Estados compõem a sociedade internacional, culmina por negar as expectativas que as normas internacionais legitimamente criam para particulares ${ }^{18}$.

Transplantadas as noções em torno da proteção diplomática para o campo do comércio internacional, duas conclusões devem ser tiradas.

A primeira é de que, conquanto as normas de Direito Internacional do Comércio possam beneficiar particulares, as eventuais violações a esses benefícios ficam à mercê do cálculo político realizado pelo Estado nacional, que decidirá sobre encaminhá-las à OMC ou não. Desse modo, da mesma forma em que nos demais campos do Direito Internacional, o encaminhamento da queixa do particular à OMC passa pelo “filtro estatal”, que é político ${ }^{19}$.

A segunda conclusão, de ordem técnica, repousa sobre o fato de que a proteção diplomática em Direito Internacional do Comércio pode assumir feições particulares em alguns pontos.

Assim, a necessidade de que os particulares esgotem as instâncias internas do Estado infrator parece não ser exigida pelos Estados nacionais antes de encaminhar as queixas à $\mathrm{OMC}^{20}$, até porque em alguns casos significaria um verdadeiro contra-senso.

A outra particularidade gira em torno da necessidade de que o particular lesado seja nacional do Estado que provoca a atuação dos órgãos multilaterais de solução de controvérsias. Certo, a proteção diplomática pode ser estendida para empresas; contudo, as normas multilaterais fazem alguma exigência de que um Estado apenas encaminhe queixas de empresas nacionais? 
O Entendimento de Solução de Controvérsias da OMC (ESC) não faz nenhuma exigência nesse sentido ${ }^{21}$; ao contrário, uma leitura superficial de seus dispositivos revela a idéia de que os direitos eventualmente lesados são sempre de titularidade dos Estados $^{22}$. O dispositivo que mais de perto trata do processo decisório que o Estado realiza quanto ao encaminhamento de uma queixa, sem, contudo, referir o contato com os particulares, é o $\S 7^{\circ}$ do art. $3^{\circ}$ : "Before bringing a case, a Member shall exercise its judgement as to whether action under these procedures would be fruitful."

Para resolver essa questão convém traçar uma analogia com as regras multilaterais que dispõem sobre a defesa comercial: a despeito das diferenças entre o processo decisório do Estado que é chamado a aplicar medidas compensatórias ou direitos antidumping com o processo decisório de encaminhar ou não uma queixa à OMC, é possível traçar certas identidades entre as duas formas de diálogo indústria-governo.

Com efeito, é disso que trata a regulamentação da defesa comercial: do acesso de particulares às instâncias governamentais para que estas coloquem em marcha os procedimentos de investigação que podem culminar com a "punição" de produtos estrangeiros subsidiados ou objeto de dumping. A principal diferença repousa em que, enquanto o diálogo fundado na aplicação de instrumentos de defesa comercial é alvo de rigorosa regulamentação, o diálogo que concerne ao encaminhamento de queixas à OMC não é, como visto. Contudo, na medida em que ambos são formas de acesso ao governo, é possível utilizar, por analogia, as regras de uma das formas de acesso na explicação da outra.

Desse modo, tanto o Acordo sobre Subsídios e Medidas Compensatórias (ASMC) quanto o Acordo Antidumping (AAD) da OMC estabelecem detalhada exigência de que as investigações de defesa comercial sejam propostas pela domestic industry ${ }^{23}$, ou seja, que o reconhecimento das reclamações sobre produtos subsidiados ou objeto de dumping só pode ser feita quando promovida pela indústria doméstica.

Parece razoável dizer que o mesmo se aplicaria para os casos de queixas cujo objeto fosse provocar as instâncias multilaterais. Se o argumento procede, pelo menos esse requisito da proteção diplomática se mostraria também presente no acesso das reclamações de particulares à OMC.

Seja como for, no Brasil não há normas que, de maneira expressa, regulem o diálogo governo-particulares, quando estes pretendem fazer que eventual prejuízo seja encaminhado à OMC. Ao que tudo indica, a formulação das decisões de "micropolítica externa” não é regulamentada e não se vislumbra a necessidade de que o Executivo informe os demais poderes acerca dos motivos que fundamentam as decisões nesse campo, como ocorre normalmente nos casos de proteção diplomática.

A experiência no direito comparado, entretanto, mostra alguns casos em que há regulamentação sobre a matéria. Isso reflete a percepção de que os 
particulares devem saber como proceder quando benefícios que lhes decorrem de acordos internacionais de comércio são violados, algo que não é comum nos demais assuntos em que os Estados exercem a proteção diplomática.

Nos EUA, se o US Trade Representative decide não iniciar o procedimento de investigação, que pode culminar com o encaminhamento, deve informar o Congresso das razões para não fazê-lo ${ }^{24}$ :

"If the Trade Representative makes a determination under subparagraph (B) not to initiate an investigation, the Trade Representative shall submit to the Congress a written report setting forth, in detail - (i) the reasons for the determination, and (ii) the United States economic interests that would be adversely affected by the investigation. ${ }^{25}$

Tratando-se de blocos regionais, é possível notar uma maior regulamentação do diálogo entre governo e setores domésticos, com vistas a encaminhar demandas aos órgãos de solução de controvérsias. O Artigo 1904.5 do NAFTA refere-se ao encaminhamento de queixas de particulares aos órgãos regionais de solução de controvérsias. A regra dispõe que:

"An involved Party on its own initiative may request review of a final determination by a panel and shall, on request of a person who would otherwise be entitled under the law of the importing Party to commence domestic procedures for judicial review of that determination, request such review." (grifado)

O dispositivo é claramente original porquanto estabelece que o particular tem direito a convocar um painel para julgar sua controvérsia. Considerando que a titularidade do pedido de constituição de um painel no NAFTA, para os casos abrangidos pelo dispositivo (direitos antidumping e medidas compensatórias), é dos Estados que formam a zona de livre comércio, o dispositivo confere ao particular um direito à proteção diplomática (“An involved Party (...) shall (...) request such review”). Trata-se de caso aparentemente sem similares no Direito Internacional.

O Direito Comunitário europeu não avança tanto quanto o NAFTA neste particular. Porém, por outro lado, a Comissão Européia centraliza a atividade de encaminhar queixas da indústria comunitária à OMC, algo ausente no NAFTA, em que a defesa da indústria nacional no foro multilateral é encargo de cada membro.

Seja como for, a Regulação de Barreiras ao Comércio ${ }^{26}$ (Trade Barriers Regulation), que substituiu o "Novo Instrumento de Política Comercial” (NIPC), estabelece os parâmetros do diálogo Comissão-indústria, com vistas a, entre outros, encaminhar reclamações à $\mathrm{OMC}^{27}$. Apesar das alterações motivadas pela necessidade de adaptar o mecanismo comunitário ao marco multilateral decorrente da Rodada Uruguai, a atuação da Comissão ainda continua passível de revisão judicial. 
Desse modo, as empresas comunitárias cuja queixa não tenha sido deferida pela Comissão - e que, portanto, não seguem para a OMC, podem acionar a Corte de Justiça das Comunidades para que uma revisão judicial da decisão da Comissão seja procedida. Nesse sentido, por exemplo, o caso Fediol, ainda na vigência do NIPC:

“1. No âmbito da aplicação do Regulamento n 2641/84, relativo à defesa contra as práticas comerciais ilícitas, as empresas que, a fim de obterem a adopção de medidas de defesa, tenham apresentado uma denúncia desatendida pela Comissão, podem pedir ao Tribunal que fiscalize a legalidade da referida decisão no caso de esta se limitar a qualificar a prática denunciada de não contrária às disposições do Acordo Geral sobre as Pautas Aduaneiras e o Comércio, sem incluir uma apreciação sobre o interesse da Comunidade na abertura de um processo de inquérito ou mesmo sobre o prejuízo ou a ameaça de prejuízo para a produção da Comunidade em questão"28

Em outros termos, o Direito Comunitário não apenas assenta os critérios que pautam a decisão da Comissão como também prevê a possibilidade de submeter as decisões ao escrutínio judicial. Evidentemente, a margem de judicial review é aquela dos atos administrativos discricionários: circunscreve-se à legalidade dos atos, sem pronunciar-se sobre a oportunidade e conveniência da decisão, que são decisões políticas.

Desse panorama delineado, vê-se que as normas de direito internacional do comércio estabelecem benefícios aos particulares, principais protagonistas do comércio internacional. Delas decorrem expectativas que fornecem o pano de fundo para o incremento da interdependência das economias nacionais.

Contudo, as expectativas que nascem da vigência de tais normas podem ser frustradas porque a regulamentação do acesso aos órgãos multilaterais de solução de controvérsias permite que permaneçam sem solução.

Disso decorre a politização das controvérsias comerciais internacionais, já que é preciso que o Estado nacional provoque o outro, o que confere ao conflito uma dimensão maior do que provavelmente teria se a empresa/indústria lesada tivesse titularidade para questionar a conduta do Estado infrator ${ }^{29}$.

A politização das controvérsias comerciais ainda produz o efeito de fazer com que a indústria doméstica prejudicada tenha de garantir bom acesso ao seu governo, o que implica, a contrario sensu, que os setores sem acesso ao governo ficam desamparados. Nessa perspectiva, a existência do "filtro político" exercido pelo Estado através da proteção diplomática confirma juridicamente a perspectiva da teoria liberal das relações internacionais nesse microcosmo: apenas chegariam à $\mathrm{OMC}$ as queixas que fossem convenientes ao governo, vale dizer, aos setores que possuem poder decisório no Estado ${ }^{30}$. 
Sob essa perspectiva, a existência de regras que estabelecem a margem de ação da administração é um avanço; a possibilidade de submeter a decisão administrativa ao controle judicial, um avanço ainda maior.

\section{O descumprimento de decisão da OMC pelo Brasil e o efeito de ricochete sobre os particulares}

O exame precedente enfocou a hipótese em que uma empresa brasileira é lesada por país membro da OMC e requer que o governo provoque a ação dos órgãos multilaterais. A análise permitiu destacar a falta de regulamentação do contato entre empresa e governo.

O presente capítulo inverte essa perspectiva e se ocupa de visualizar os casos em que o Brasil é “acionado" por outro membro da OMC e é considerado infrator, de modo que as medidas adotas pelo Brasil, ipso facto, devem ser retiradas. O objetivo é mostrar como, também aqui, a falta de diálogo institucionalizado no Brasil pode trazer prejuízo a particulares.

A solução de controvérsias na OMC é regida pelo Entendimento de Solução de Controvérsias (ESC). O Art. 21.1 do ESC determina que o Estado perdedor deve adotar medidas para garantir pleno cumprimento das decisões do OSC, em um período a ser informado em reunião dentro de 30 dias da adoção da decisão final (Art. 21.3). O Membro perdedor pode, ao invés de adequar-se às normas que violou, oferecer compensações ao Estado ganhador (Art. 22.1).

No entanto, se o Estado perdedor não retirar a medida violatória e as compensações eventualmente oferecidas não forem aceitas, o Art. 22.2 autoriza o ganhador a requerer a suspensão de concessões atribuídas ao infrator.

As concessões que podem ser suspensas são, na verdade, as condições de acesso ao mercado do Estado ganhador que os produtos provenientes do Estado perdedor fariam jus em virtude dos compromissos assumidos nas rodadas de negociação. A sanção decorrente da atividade do OSC nada mais é do que o retorno da relação entre os países envolvidos na controvérsia ao estado anterior às negociações.

A imposição da sanção é organizada pelo Entendimento. Com efeito, o parágrafo $3^{\circ}$ do Art. 22 estabelece que a suspensão deve atingir: (a) em primeiro lugar, o mesmo setor do produto que ensejou a controvérsia; (b) em hipótese secundária, outros setores regidos pelo mesmo $\operatorname{ccordo}^{31}$; (c) e, em último caso, a sanção pode incidir sobre concessões decorrentes de outro acordo.

A leitura do Artigo, assim, mostra que é possível que uma disputa envolvendo um setor da economia doméstica (aviação civil, produtos agrícolas, etc) possa produzir efeitos em outros setores, na hipótese do Estado não cumprir a decisão final expedida pelo OSC. 
Isso, na verdade, não é algo novo no ambiente do Direito Internacional; trata-se, ao contrário, de uma característica que define um de seus traços clássicos, a responsabilidade coletiva ${ }^{32}$, i.e., a punição de toda a coletividade pelo ilícito internacional praticado em nome do Estado.

A particularidade que as normas de Direito Internacional do Comércio reclamam, contudo, repousa sobre o fato apontado anteriormente: é preciso que os setores que serão atingidos por ricochete não apenas saibam disso mas, sobretudo, que possam participar do processo governamental que envolve as decisões sobre o cumprimento (ou sobre como cumprir) as determinações do OSC.

De que forma o governo dialoga com os setores que podem ser atingidos por tais sanções?

Sem dúvida, a regulamentação mais precisa acerca do assunto é aquela que estabelece o procedimento seguido pelo USTR. Desse modo, circulada a decisão da OMC o USTR deve comunicar os órgãos competentes no Poder Legislativo para debater o cumprimento da decisão:

"Promptly after the circulation of a report of a panel or of the Apellate Body to WTO members in a proceeding described in subsection (d) of this section, the Trade Representative shall (...) (3) if the report is adverse to the United States, consult with the appropriate congressional committees concerning whether to implement the report's recommendation and, if so, the manner of such implementation and the period of time needed for such implementation." ${ }^{33}$

Além disso, as partes que possam ter interesse no desdobramento da controvérsia tem a possibilidade de apresentar seus comentários antes que a decisão do USTR sobre o cumprimento seja expedida:

“(...) (d) Opportunity for comment by interested parties: Prior to issuing a determination under this section, the administering authority or the Commission, as the case may be, shall provide interested parties with an opportunity to submit written comments and, in appropriate cases, may hold a hearing, with respect to the determination.”34

O Brasil, por sua vez, não possui uma regulamentação sobre o acesso dos setores da economia doméstica que podem ser atingidos por sanções impostas por outros Estados contra o país. Desse modo, o diálogo é feito de forma casuística e não necessariamente conduzido pelo Ministério das Relações Exteriores.

Ausente ou não a regulamentação, certo é que mesmo nos casos em que os setores domésticos têm acesso previsto às instâncias governamentais, a decisão final de cumprimento (ou descumprimento) pode não satisfazer às expectativas de todos: volta-se, também nesse ponto, ao filtro político exercido pelo Estado, na medida em que a decisão sobre como reagir à determinação multilateral é, apesar do diálogo, do governo ${ }^{35}$. 
A questão que necessariamente segue é: podem os setores atingidos por ricochete pela suspensão de concessões exigir de seu governo reparação nas instâncias judiciárias domésticas?

A atuação das instâncias judiciárias em questões que dizem respeito à condução de política externa tem crescido em virtude do aumento de normas internacionais que produzem efeitos domésticos ${ }^{36}$.

Uma análise aprofundada desse particular não é aqui cabível, mas cumpre assinalar que a simples possibilidade de decisões judiciais pronunciarem-se sobre matérias relativas à política externa representa uma certa relativização na concepção monopolística da condução dos negócios externos pelo Poder Executivo; vale dizer, a possibilidade de submeter os atos praticados pelo Executivo à análise judicial (nos mais variados graus de análise, bem entendido) mostra que as "conseqüências judiciais” das decisões de política externa passarão a ser consideradas pelo Executivo.

Assim, por um lado, reconhece-se que o Executivo é o Poder com maior aptidão para representação externa do Estado e mantém-se em suas mãos a competência de conduzir os assuntos estrangeiros ${ }^{37}$; por outro, entretanto, o aumento da atuação judicial em casos referentes a temas internacionais mostra ao Executivo que suas decisões têm um “custo”, cobrado pelo Judiciário. Na medida em que a tripartição de poderes é um dos pilares dos Estados modernos, é preciso delimitar a área de atuação do Judiciário frente à do Poder Executivo nos assuntos que digam respeito à política externa. Assentados os limites, poder-se-á proceder ao exame da possibilidade de cobrar, através do Judiciário, o ressarcimento que os atos do Executivo produziram aos nacionais.

O tratamento contemporâneo dispensado aos atos de política externa deve ser inserido no contexto dos atos administrativos discricionários: aqueles em torno de cuja adoção o Poder Judiciário não se manifesta acerca da oportunidade tampouco da conveniência, decisões que soberanamente competem ao Poder Executivo. A análise judicial, contudo, existe e aborda a legalidade do ato, com a principal finalidade de apreciar o respeito aos poderes constitucionalmente distribuídos ao Executivo ${ }^{38}$.

Desse modo, fica afastada a tradicional doutrina que via nos atos de política externa uma categoria sui generis, a dos atos políticos, os quais transitavam à margem de qualquer controle judicial.

A classificação dos atos de política externa como atos discricionários implica, portanto, reconhecer que certos aspectos da decisão não são analisados pelo Judiciário (e, portanto, são considerados non-justiciable questions), ao passo que outros podem desafiar a judicial review.

Essa delimitação é visível na jurisprudência norte-americana das political questions: 
"War - Constitutionality of war in Indochina - President's power to continue hostilities - whether formal declaration of war necessary - political question (...) The court concluded that the question whether the President had exceeded his constitutional authority in continuing to prosecute the war was a political question which the court could not decide.”39

A jurisprudência brasileira sobre atos políticos parece correr em sentido similar. Dada a falta de precedentes específicos para o controle judicial sobre atos de política externa, é por analogia que se traça o argumento:

"Questão política . Quando não escapa ao conhecimento do Poder Judiciário. As medidas políticas são discricionárias apenas no sentido em que pertencem à discrição do Congresso ou do Governo os aspectos de sua conveniência ou oportunidade a apreciação das circunstâncias que possam autorizá-las. Mas a discrição legislativa ou administrativa não pode exercitar-se fora dos limites constitucionais ou legais. O antigo critério jurisprudencial norte-americano (merely, purely, exclusively political questions) foi superado." ${ }^{20}$

O pedido de indenização para particulares, decorrente de prejuízo advindo de sanção imposta contra o Brasil pelo OSC é passível de ser feita pela via judicial? Ou, ao contrário, a decisão do governo brasileiro - entendida pelo OSC como violatória - deriva do âmbito de discricionariedade gozado pelo governo brasileiro e, portanto, alheia ao controle judicial?

$\mathrm{Na}$ medida em que a jurisprudência nacional ainda não contempla precedentes nessa área (na verdade, nem mesmo a jurisprudência internacional), segue uma análise que especula tanto os fundamentos para deferir quanto para indeferir o pedido indenizatório.

\section{Uma especulação em torno do indeferimento do pedido de indenização}

O Poder Judiciário não está dotado dos mesmos meios que o Poder Executivo para lidar com problemas de política externa. Eis uma das razões que justifica não apenas a pouca jurisprudência sobre assuntos internacionais mas também a timidez ${ }^{41}$ dos juízes diante da necessidade de decidir tais matérias, quando inevitável:

"Perhaps it is because it is so difficult to reconcile the foregoing definition of Art. III judicial power with the broad range of vitally important day-to-day questions regularly decided by Congress or the Executive, without either challenge or interference by the Judiciary, that the decisions of the Court in this area have been rare, episodic, and afford little precedential value for subsequent cases. The tensions present in any exercise of executive power under the tripartite system of Federal Government established by the Constitution have been reflected in opinions by Members of this Court more than once." ${ }^{42}$ 
Essa timidez traduz-se nas mais variadas regras adotadas pelos tribunais, que culminam por restringir a margem de apreciação que os juízes gozam sobre os atos ligados às relações internacionais; certamente a regra mais notória dessa espécie é a da imunidade de jurisdição dos Estados estrangeiros: através dela, os Estados estrangeiros não podem ser réus perante os tribunais de outros países, sob pena de violar a sua soberania ${ }^{43}$. Em outras palavras, a regra implica dizer que o tratamento de um Estado com os demais é feito pelo Executivo, e não pelo Judiciário.

Projetando o argumento para a análise empreendida, temos que, se o ato de política externa for considerado integralmente de competência do Executivo e que, portanto, o Judiciário não apreciaria nem mesmo os pedidos de indenizações deles decorrentes, estaríamos diante da versão judicial para o argumento "realista" da especificidade da política externa ${ }^{44}$. Ou seja, o Executivo surgiria como árbitro dos interesses dos nacionais eventualmente envolvidos na condução da política externa e o Judiciário, órgão inapto para lidar com esses problemas, não analisaria nem mesmo os pedidos de indenização decorrentes dos prejuízos advindos da condução da política externa.

De uma certa maneira, é isso que decorre da jurisprudência consolidada na Corte de Justiça das Comunidades Européias (CJCE) quando se trata de atribuir vigência comunitária às normas multilaterais e às decisões dos órgãos da OMC. Com efeito, a jurisprudência comunitária assentou a ausência de efeito direto às disposições multilaterais que, portanto, não podem servir de fundamento de recursos de particulares e Estados membros contra os órgãos comunitários.

Em caso recente, na esteira da decisão do caso Bananas, um particular invocou em um Recurso de Anulação contra a Comissão o disposto em um relatório da OMC. A parte relevante da ementa dispõe que:

"Um operador econômico não pode invocar um relatório do Órgão de Recurso Permanente da Organização Mundial do Comércio (OMC), nem a decisão pela qual o Órgão de Resolução de Litígios da OMC aprovou esse relatório, para sustentar que o sistema de organização comum dos mercados no sector da banana, instituído pelo Regulamento no 404/93, já não existe. (...). Além disso, para que uma disposição de uma decisão de que o interessado não seja destinatário possa ter efeito directo em relação a ele tal disposição deverá impor ao destinatário uma obrigação incondicional e suficientemente clara e precisa a favor do interessado." ${ }^{\text {45 }}$

A argumentação da CJCE alinha-se ao raciocínio, aventado acima, de que as normas multilaterais não criam direitos para os particulares; a peculiaridade do raciocínio da Corte, não obstante, está em considerar que os particulares estão despidos de direito subjetivo porque as disposições das normas multilaterais são “amplas” - de modo a não deixar claro qual o direito decorrente da norma - e também porque o regime multilateral prevê a possibilidade de que os Estados 
resolvam negociadamente as controvérsias. A falta de locus standi aos órgãos da OMC não é discutida:

"O Acordo Geral sobre Pautas Aduaneiras e Comércio [GATT] não contém disposições susceptíveis de conferir aos particulares direitos que estes possam invocar perante os órgãos jurisdicionais nacionais para se opor à aplicação de disposições nacionais contrárias. Com efeito, as particularidades do referido acordo, que se caracteriza por uma grande flexibilidade das suas disposições, designadamente das que dizem respeito às possibilidades de derrogação, às medidas que podem ser tomadas perante dificuldades excepcionais e à composição dos diferendos entre as partes contratantes, opõe-se à criação desses direitos." ${ }^{46}$

\section{Uma especulação em torno da possibilidade de exigir a reparação}

Melhor argumento parece repousar sobre o deferimento do pedido de reparação. A idéia de que os benefícios concedidos pelas normas internacionais aos indivíduos são de disposição exclusiva dos Estados dos quais são nacionais desafia a lógica subjacente aos Estados democráticos.

Certo, o indivíduo não possui direito subjetivo decorrente das normas internacionais; não obstante, isso não implica dizer que a expectativa criada pela norma internacional não possa ser protegida e assegurada nos casos de frustração.

A própria jurisprudência norte-americana considera que os prejuízos decorrentes de atos de política externa são passíveis de “cobrança” pelo Judiciário. No caso Dames \& Moore v. Regan, a Suprema Corte entendeu que era passível de controle judicial a apreciação dos prejuízos decorrentes de decisão presidencial que sustava a constrição sobre bens iranianos sob jurisdição norte-americana ${ }^{47}$.

"The possibility that the President's actions with respect to the suspension of the claims may effect a taking of petitioner's property in violation of the Fifth Amendment in the absence of just compensation makes ripe for adjudication the question whether petitioner will have a remedy at law in the Court of Claims." (ementa)

O direito brasileiro possui, na Constituição, regra clara que serve de argumento para sustentar o pedido de reparação pelos prejuízos decorrentes de atos de política externa. Assim, o art. $5^{\circ}$, § XXXV estabelece que toda a lesão ao direito pode ser objeto de pedido de reparação ao Judiciário: “a lei não excluirá da apreciação do Poder Judiciário lesão ou ameaça a direito.”

Ainda, se for considerado que, pela Constituição brasileira, a responsabilidade do Estado é objetiva, pode-se afirmar que as expectativas derivadas dos compromissos internacionais assumidos pelo país não devem ser 
frustradas, sob pena de reparação. Isso porque, não se perquirindo das razões motivadoras da decisão tomada pelo governo, basta a demonstração do nexo causal entre a decisão e o dano provocado ao particular.

Nesse sentido, o art. $37, \S 6^{\circ}$, dispõe que: “As pessoas jurídicas de direito público e as de direito privado prestadoras de serviços públicos responderão pelos danos que seus agentes, nessa qualidade, causarem a terceiros (...)”.

Que conseqüências produz a aceitação pelo Judiciário de pedidos de indenização frente aos atos lesivos praticados pelo Executivo, no âmbito da condução da política externa?

A conseqüência mais imediata é mostrar que o Judiciário surge como espaço no qual, domestica e institucionalizadamente, a política externa é discutida. Com efeito, apesar de tratar-se de análise posterior, a formação de jurisprudência consagrando a responsabilidade do Executivo nesses casos cria, inegavelmente, a "sombra" que se projeta para os casos futuros, para fazer com que os "custos judiciais” das decisões governamentais sejam tomados em conta.

Sob uma perspectiva mediata e teórica, a participação indireta do Judiciário demanda uma releitura da teoria liberal das relações internacionais: se a política externa de um Estado não é senão a projeção internacional dos interesses das elites que têm acesso ao governo ${ }^{48}$, o acesso ao Judiciário permite que os setores preteridos na decisão governamental possam ter voz, ainda que isso requeira a produção de danos a esses setores. Em outros termos, a teoria liberal considera que a participação na política externa é apenas aquela que tem lugar nas esferas decisórias do governo, quando o papel que o Judiciário pode ocupar nesse cenário, ainda que em condições particulares, não deve ser desprezado.

Outubro de 2002

\section{Notas}

1 Apud “Mr. Diplomat”, in Foreign Policy, July/August 2001, p.40

2 O que decorre da perspectiva da atividade diplomática como um jogo de dois níveis, no sentido de Putnam: "The politics of many international negotiations can usefully be conceived as a two-level game. At the national level, domestic groups pursue their interests by pressuring the government to adopt favorable policies, and politicians seek power by constructing coalitions among those groups. At the international level, national governments seek to maximize their own ability to satisfy domestic pressures, while minimizing the adverse consequences of foreign developments.” (PUTNAM, Robert. Diplomacy and domestic politics: the logic of two-level games. International Organization, v. 42, n. 3, 1988, p. 434)

"[i]n the liberal conception of domestic politics, the state is not an actor but a representative institution constantly subject to capture and recapture, construction and reconstruction by coalitions of social actors. Representative institutions and practices constitute the critical 'transmission belt' by which the preferences and social power of individuals and groups are translated into state policy. Individuals turn to the state to achieve goals that private behavior 
is unable to achieve efficiently. Government policy is therefore constrained by the underlying identities, interests, and power of individuals and groups (inside and outside the state apparatus) who constantly pressure the central decision makers to pursue policies consistent with their preferences” (MORAVCSIK, Andrew, Taking preferences seriously: a liberal theory of international politics, International Organization, v. 51 (4), 1997, p. 518). Nesse particular, o postulado liberal identifica-se com a visão marxista sobre a formulação da política externa. A respeito, KRASNER, Stephen. Defending the national interest. Princeton: Princeton University Press, 1978, p.5.

$4 \quad$ Op cit., p. 28

5 "Quanto mais numerosos forem os elementos de pluralidade, comunicação e participação em um sistema, mais difícil será para suas elites e seus grupos de interesse permanecerem hegemônicos, e o fator mais sujeito a alterações é o equilíbrio entre seus diversos níveis e fluxos de comunicações e decisões políticas internas e externas.” (DEUTSCH, Karl. Análise das relações internacionais. $2^{\mathrm{a}}$. ed. Brasília: Editora UnB, 1982, p.151)

6 Que é um capítulo da legalização das relações internacionais, nos termos propostos por GOLDSTEIN, KAHLER, KEOHANE e SLAUGHTER (International Organization, v. 54, n. 3, 2000).

7 Com a globalização, “a diplomacia amplia o seu alcance. Deixa de ser um modo privilegiado de diálogo entre Estados e passa a tecer uma complexa teia de atores, de lealdades variadas. Neste sentido, estamos diante de uma nova diplomacia, que se orientaria por três linhas básicas de preocupação: i. o cuidado com a construção de regras de convivência internacional: classicamente, as regras tinham escopo limitado (alianças com vistas a segurança, tarifas comerciais, etc.) e eram redigidas em negociações diplomáticas em que prevalecia o interesse estratégico. Hoje, o processo é sensivelmente mais complexo, porque os temas são extremamente variados, alguns de alta complexidade técnica, e, muitas vezes, o processo de discernir o melhor interesse nacional não é evidente.; ii. a necessidade de lidar com os impulsos internos: exatamente em função da variedade de seus temas e do fato de que trazem repercussões diretas sobre interesses de setores nacionais, o processo de formulação de posições diplomáticas, no quadro democrático, passa a integrar a lógica do cálculo realista das possibilidades de agir e a lógica dos ganhose custos dos grupos sociais, afetados pelas opções diplomáticas concretas (...).; iii. a variedade de interlocutores (...)” (LAFER, Celso \& FONSECA JR., Gelson. Questões para a diplomacia no contexto internacional das polaridades indefinidas (notas analíticas e algumas sugestões), in FONSECA JR., Gelson \& NABUCO DE CASTRO, Sérgio Henrique (orgs.). Temas de Política Externa Brasileira II. Vol. 1, FUNAG-Paz e Terra: Brasília-São Paulo, 1997, p. 73, grifado); ver também HIRST, Mônica \& SOARES DE LIMA, Maria Regina. Contexto internacional, democracia e política externa. Política Externa, v. 11, n. 2, 2002, p. 88.

O que dota o diálogo diplomático de "dialetos" aos quais os agentes políticos externos não estavam acostumados: o das normas jurídicas (quando as discussões internacionais são travadas perante órgãos judiciais, como é o Órgão de Apelação da OMC) e o da lógica econômica. Aliás, o aumento da legalização dos regimes internacionais destaca a necessidade da formação de uma “diplomacia jurídica”, i.e., a formação de diplomatas que transitem com desenvoltura dentro do ambiente do Direito Internacional e dos regimes, cada vez mais específicos, que existem ("Legal commitments mobilize legally oriented interest and advocacy groups, such as the organized bar, and legitimize their participation in domestic decision making. They also expand the role of legal bureaucracies within foreign offices and other government agencies." (ABBOTT, Kenneth W. \& SNIDAL, Duncan. Hard and soft law in international governance. International Organization, v. 54, n. 3, 2000, p.44)). Nesse sentido, a criação da Cordenação-Geral de Contenciosos, na gestão Lafer, é um sinal da atualização institucional do Itamaraty nesse sentido. Da mesma forma, no campo econômico, a reestruturação operada na área econômica do Ministério: “A crescente complexidade técnica e a semelhança das pautas negociadoras levou-me a determinar 
a reestruturação da área econômica do Itamaraty. Com unidades administrativas organizadas em função de temas, e não mais com base nos foros negociadores, será possível operar com maior eficiência e coerência." (Balanço das atividades do Itamaraty ao longo do último ano - Intervenção CEP. Curitiba, 19 de abril de 2002, MRE: Informações à imprensa, n. 179, 19/04/2002).

US - Sections 301-310 of the Trade Act of 1974 (OMC, Relatório do Painel, WT/DS152/R), §7.76: “The security and predictability in question are of the 'multilateral trading system'. The multilateral trading system is, per force, composed not only of States, but also, indeed mostly, of individual economic operators. The lack of security and predictability affects mostly these individual operators.”; no mesmo sentido KESSIE, Edwini. Enhancing security and predictability for private business operators under the Dispute Settlement System of the WTO. Journal of World Trade, v. 34, n. 6, 2000, p. 2; também KEOHANE, Robert O. Problematic lucidity. Stephen Krasner's "State power and the structure of international trade”. World Politics, v. 50, n. 1, 1997, p.150

10 Daí traduzir International Trade Law como Direito Internacional do Comércio, ramo do Direito Internacional Público, em oposição ao Direito do Comércio Internacional, que se ocupa das relações privadas travadas entre os agentes do comércio internacional.

11 Que compreende a estrutura institucional - o Órgão de Solução de Controvérsias, painéis ad hoc e o Órgão de Apelação - e também as normas e jurisprudência que regulam o procedimento de litígios envolvendo membros da OMC em decorrência da violação de um dos acordos fiscalizados pela Organização.

12 KELSEN, Hans. Teoria Geral do Direito e do Estado. $3^{\text {a }}$ ed., 2 ${ }^{\text {a }}$. tiragem. São Paulo: Martins Fontes, 2000, p. 494.

13 Não entrarei na discussão da aceitação, na jurisprudência da OMC, dos amicus curiae briefs tampouco da utilização de advogados trazidos pelos particulares envolvidos no litígio, na medida em que não falseiam o ponto principal, que é a dependência do particular ao Estado. A respeito dessa forma de participação dos non-state actors no procedimento de solução de controvérsias na OMC, ver HERNÁNDEZ-LÓPEZ, Ernesto. Recent trends and perspectives for non-state actor participation in World Trade Organization disputes. Journal of World Trade, v. 35, n. 3, 2001, p. 469-498.

14 "Private parties who have experienced market access problems would first have to petition their governments which may then decide whether or not to lodge a formal complaint at the WTO.” (KESSIE, op. cit., p.4), também MAVROIDIS et allii. Is the WTO Dispute Settlement Mechanism responsive to the needs of the traders? Would a system of direct action by private parties yield better results?. Journal of World Trade, v. 32, n. 2, 1998, p. 147;. a regulamentação norte-americana sinaliza claramente para a existência da proteção diplomática, ao permitir a discricionariedade do USTR em conduzir uma queixa adiante: "The Trade Representative is not required under subparagraph (A) to initiate an investigation under this subchapter with respect to any act, policy, or practice of a foreign country if the Trade Representative determines that the initiation of the investigation would be detrimental to United States economic interests." (19 U.S.C., § 2412, (b), (2), (B), grifado); “(...) a Embraer é uma companhia competitiva, responsável por um desempenho exportador importante de produtos de alta tecnologia. Enquanto tal ela é já por si só merecedora do respaldo do governo brasileiro. Aliás esse é um caso típico do que se chama de proteção diplomática porque só se chega ao sistema de solução de controvérsias da OMC se um país membro entende que o interesse da empresa corresponde ao interesse nacional.” (Briefing concedido pelo Sr. Ministro das Relações Exteriores, Prof. Celso Lafer. MRE: Informação à Imprensa, n. 33, 28/01/2002, grifado)

15 Draft article 1, International Law Commission, First report on diplomatic protection, $52^{\mathrm{a}}$ Sessão, 2000, A/CN.4/506, p. 11.

16 “Le préjudice subi par une personne privée et résultant d'une violation du droit international ne donne pas en soi un droit à la victime d’obtenir réparation. En revanche, 'son' Etat national peut 
prendre 'fait et cause' pour elle et 'endosser' sa réclamation. Ce faisant, le conflit appartient alors à l'ordre international et il devra être tranché sur la base du droit international, dans la mesure où, désormais, il va opposer deux Etats.” (CARREAU, Dominique. Droit International. $4^{\mathrm{a}}$ ed., Paris: Pedone, 1994, p.432)

17 “Ce mécanisme classique d' 'endossement' par l'Etat national est potentiellement injuste pour l'individu. En effet, l’Etat national peut s'abstenir de le protéger ou peut aboutir, pour des raisons d'Etat, à un accord partiel qui ne satisfasse pas l'individu lesé.” (CARREAU, op. cit., p.434, grifado no original)

18 “Cette construction n'est évidemment pas satisfaisante du point de vue de la technique juridique, ni même de la simple logique, car elle repose sur une fiction juridique évidente: l'indentification de l'individu intéressé et de l'Etat dont il est le national.” (SCELLE, Georges. Droit International. Paris: Domat-Montchrestien, 1944, p.417)

“(...) export interests must operate through a government filter. If there is a high probability that the government will not be willing to bring the dispute to the WTO, cases may not be brought. Governments may not want to bring cases to the WTO for fear of stimulating counter claims (the 'glass house' syndrome)” (HOEKMAN, Bernard \& KOSTECKI, Michel. The political economy of the World Trading System. $2^{\mathrm{a}}$ ed., Oxford: Oxford University Press, 2001, p.87) A minuta de acordo sobre solução de controvérsias na ALCA é, no Direito Internacional do Comércio, um caso quase excepcional; o número 20 da minuta estabelece: "Nos casos em que o direito internacional exigir a exaustão dos recursos locais, nenhuma controvérsia existente entre as Partes deverá ser submetida aos procedimentos estipulados no presente capítulo, salvo e até que tal requisito tenha sido satisfeito atendido.”

21 Nas controvérsias entre os membros do Mercosul, o Protocolo de Brasília (art. 26, §1 ${ }^{\circ}$ ) faz a exigência da nacionalidade da queixa quando se tratar de reclamações de particulares, ao estabelecer que: “Os particulares afetados formalizarão as reclamações ante a Seção Nacional do Grupo Mercado Comum do Estado Parte onde tenham sua residência habitual ou a sede de seus negócios. ”(grifado). O Protocolo de Olivos, que substitui o de Brasília, mantém a regra em seu artigo 40, $\S 1^{\circ}$.

22 Por exemplo, o art. $3^{\circ}, \S 2^{\circ}$ estabelece que "Members recognize that it serves to preserve the rights and obligations of Members under the covered agreements (...)"

23 O conceito de indústria doméstica, encontrado tanto no art. 16 do ASMC quanto no art. $4^{\circ}$ do AAD, é similar nos dois acordos: “(...) the term "domestic industry” shall be interpreted as referring to the domestic producers as a whole of the like products or to those of them whose collective output of the products constitutes a major proportion of the total domestic production of those products (...)"

24 “(...) de forma geral, é ainda hoje possível ao USTR iniciar ou não um processo de inquérito face a um caso concreto (...) e, portanto, é exacto que a sua competência não é susceptível de fiscalização jurisdicional.” (Conclusões do Advogado-Geral Van Gerven no caso Fediol Federação da Indústria Oleícola da CEE contra Comissão das Comunidades Européias, Processo 70/87, Coletânea da Jurisprudência do Tribunal de Justiça das Comunidades Européias, 1989-6, p. 1811).

19 U.S.C., § 2412, (b), (2), (C).

Regulamento 3286/94.

RYDELSKI, Michael Sánchez \& ZONNEKEYN, G.A.V.R. The EC Trade Barriers Regulation. Journal of World Trade, v. 31, n. 5, 1997, p. 159.

Op. cit., p. 1782.

A solução seria atribuir acesso direto à OMC aos particulares? A questão é controvertida porque opõe a necessidade de satisfazer os beneficiários das normas multilaterais às restrições orçamentárias da Organização, que teria o volume de trabalho aumentado exponencialmente. Bronckers opta pelo acesso direto: “As long as non-judicial remedies result in government-to- 
government disputes, there will be political inhibitions to using them. The only way to change this and remove these inhibitors is to give private parties direct access to international nonjudicial remedies.” (BRONCKERS, Marco C.E.J., Non-judicial and judicial remedies in international trade disputes: some reflections at the close of the Uruguay Round. Journal of World Trade, v. 24, n. 6, 1990, p. 122)

30 E é por tal razão que alguns regimes internacionais (sobretudo os regimes europeu e interamericano de proteção aos direitos humanos) atribuem aos particulares lesados acesso direto às instâncias internacionais, dispensando a "tutela” de seu Estado; aliás, os particulares são autorizados inclusive a provocar os órgãos internacionais contra seus Estados nacionais. Nesse cenário, em que a proteção diplomática é deixada de lado, a teoria liberal perde confirmação.

31 Os acordos multilaterais, administrados pela OMC, que compõem o single undertaking, i.e., obrigam todos os membros da Organização, são o GATT, o GATS e o TRIPS.

KELSEN, Hans. Derecho y paz en las relaciones internacionales. Cidade do México: Fondo de Cultura Económica, 2a ${ }^{a}$ ed, 1ª reimpressão, 1996, p. 124-8.

33 19 U.S.C., § 3533, (f), grifado.

34 19 U.S.C., § 3538.

35 "Member States may have mechanisms to incorporate non-State actors. These mechanisms do not require Members to listen or incorporate non-State views.” (HERNÁNDEZ-LÓPEZ, op. cit., p.476)

36 Slaughter e Bosco cunharam o termo plaintiff's diplomacy para designar a litigância em torno de questões de política externa: “(...) new forms of litigation can have powerful and wide-ranging consequences, both intended and unforeseen. This is specially obvious in one area long thought outside the power of domestic courts: foreign policy. Increasing numbers of individuals, including torture and terrorrism victims, Holocaust survivors, and denizens of dwindling Amazon rain forest, are now using lawsuits to defend their rights under international law.” (SLAUGHTER, Anne-Marie \& BOSCO, David. Plaintiff's diplomacy. Foreign affairs, v. 79, n. 5, 2000, p. 102)

37 Nos termos assentados, de forma que se tornou clássica, por Hamilton nos Federalist Papers, n. 75 (edição da Encyclopaedia Britannica, 19ª. reimpressão, 1971, p. 222-225).

38 A respeito GORDILLO, Agustín. Tratado de Derecho Administrativo. Tomo 2, $3^{\text {a }}$ ed.. Buenos Aires: Fundación de Derecho Administrativo, 1998, p. 40-52.

39 Mitchell v. Laird, 476 F. $2^{\text {nd }} .533$, US Court of Appeals, District of Columbia Circuit, 20/03/ 1973.

40 STF, Mandado de Segurança 1423/DF, Tribunal Pleno, Rel. Min. Luiz Galotti, julgado em 22/ 01/1951.

41 A expressão é empregada em DINH, Nguyen Quoc; PELLET, Alain e DAILLIER, Patrick. La timidité du juge dans l'exercice de ses compétences. Droit Internacional Public. 6a. ed, Paris: LGDJ, 1999, p. 235.

42 Dames \& Moore v. Regan, 453 U.S. 654 (1981), Opinião da Corte, pelo Justice Rehnquist.

43 Mesmo que se considere a regra na forma relativa, como vige atualmente.

44 Desenvolvido de forma excelente por SOARES DE LIMA, Maria Regina. Instituições democráticas e política exterior. Contexto internacional, v. 22, n. 2, 2000.

45 Fruchthandelsgesellschaft mbH Chemnitz contra Comissão das Comunidades Européias, Processo T-254/97, Colectânea da Jurisprudência do Tribunal de Justiça e do Tribunal de Primeira Instância, Parte II, 1999 - 9/10, p. 2744.

46 Amministrazione delle finanze dello Stato contra Chiquita Italia SpA (decisão prejudicial), Processo C-469/93, Colectânea, Parte I, 1995-12, p. 4534.

47 Mesmo que no caso se tratasse de determinar se o recorrente teria acesso à Claims Commission criada pelo Acordo de Alger para que norte-americanos pudessem ressarcir-se contra o Irã dos prejuízos sofridos. 
48 "States do not act; the decision-making elites in states act on behalf of the state." (AREND, Anthony Clark, Toward an understanding of international legal rules, in BECK, Robert et alii, International Rules - Approaches from international law and international relations. Oxford: Oxford University Press, 1996, p.294, grifado no original).

\section{Bibliografia}

ABBOTT, Kenneth W \& SNIDAL. Duncan. Hard and soft law in international governance. International Organization, v. 54, n. 3, 2000, p.44.

AREND, Anthony Clark. Toward an understanding of international legal rules, in BECK, Robert et alii. International Rules - Approaches from international law and international relations. Oxford, Oxford University Press, 1996, p.294

BRONCKERS, Marco C.E.J. Non-judicial and judicial remedies in international trade disputes: some reflections at the close of the Uruguay Round. Journal of World Trade, v.24, n.6, 1990, p. 122.

CARREAU, Dominique. Droit International. 4a ed., Paris: Pedone, 1994, p.432.

DEUTSCH, Karl. Análise das relações internacionais. 2ª ed. Brasília: Editora UnB, 1982, p.151.

DINH, Nguyen Quoc; PELLET, Alain e DAILLIER, Patrick. Droit Internacional Public. 6a . ed, Paris: LGDJ, 1999, p. 235.

GOLDSTEIN, Judith; KAHLER, Miles; KEOHANE, Robert e SLAUGHTER, Anne-Marie (eds.). Legalization and World Politics . International Organization, v. 54, n. 3, 2000.

GORDILLO, Agustín. Tratado de Derecho Administrativo. Tomo 2, $3^{\text {a }}$ ed.. Buenos Aires: Fundación de Derecho Administrativo, 1998, p. 40-52.

HERNÁNDEZ-LÓPEZ, Ernesto. Recent trends and perspectives for non-state actor participation in World Trade Organization disputes. Journal of World Trade, v. 35, n. 3, 2001, p. 469-498.

HIRST, Mônica \& SOARES DE LIMA, Maria Regina. Contexto internacional, democracia e política externa. Política Externa, v. 11, n. 2, 2002, p. 88.

HOEKMAN, Bernard \& KOSTECKI, Michel. The political economy of the World Trading System. $2^{a}$ ed., Oxford: Oxford University Press, 2001, p.87.

KELSEN, Hans. Derecho y paz en las relaciones internacionales. Cidade do México: Fondo de Cultura Económica, $2^{\mathrm{a}}$. ed, $1^{\mathrm{a}}$. reimpressão, 1996, p. 124-8.

KELSEN, Hans. Teoria Geral do Direito e do Estado. $3^{\text {a }}$ ed., 2 2a tiragem. São Paulo: Martins Fontes, 2000, p. 494.

KESSIE, Edwini. Enhancing security and predictability for private business operators under the Dispute Settlement System of the WTO. Journal of World Trade, v. 34, n. 6, 2000, p. 2.

KEOHANE, Robert O. Problematic lucidity. Stephen Krasner's "State power and the structure of international trade”. World Politics, v. 50, n. 1, 1997, p.150.

KRASNER, Stephen. Defending the national interest. Princeton: Princeton University Press, 1978, p.5.

LAFER, Celso \& FONSECA JR., Gelson. Questões para a diplomacia no contexto internacional das polaridades indefinidas (notas analíticas e algumas sugestões), in FONSECA JR., Gelson. \& NABUCO DE CASTRO, Sérgio Henrique (orgs.). Temas de Política Externa Brasileira II. Vol. 1, Brasília-São Paulo: FUNAG-Paz e Terra, 1997, p. 73.

MAVROIDIS, Petros et allii. Is the WTO Dispute Settlement Mechanism responsive to the needs of the traders? Would a system of direct action by private parties yield better results?. Journal of World Trade, v. 32, n.2, 1998, p. 147.

MORAVCSIK, Andrew, Taking preferences seriously: a liberal theory of international politics. International Organization, v. 51, n. 4, 1997, p. 518.

PUTNAM, Robert. Diplomacy and domestic politics: the logic of two-level games. International Organization, v. 42, n. 3, 1988, p. 434. 
RYDELSKI, Michael Sánchez \& ZONNEKEYN, G.A.V.R. The EC Trade Barriers Regulation. Journal of World Trade, v. 31, n. 5, 1997, p. 159.

SCELLE, Georges. Droit International. Paris: Domat-Montchrestien, 1944, p.417.

SLAUGHTER, Anne-Marie \& BOSCO, David. Plaintiff's diplomacy. Foreign affairs, v. 79, n. 5, 2000, p. 102.

SOARES DE LIMA, Maria Regina. Instituições democráticas e política exterior. Contexto internacional, v. 22, n. 2, 2000.

\section{Resumo}

Os juristas têm desprezado o estudo da formulação da política externa. A despeito disso, o Direito Internacional do Comércio coloca os Estados em uma posição na qual a diplomacia se confunde com a defesa dos interesses dos particulares beneficiados com tais normas. Nesse sentido, a política comercial externa deveria ser a resultante do diálogo entre governo e particulares interessados. Em tal diálogo, as normas jurídicas desempenhariam a importante função de tornar melhor o controle da formulação da política externa. O presente artigo analisa este argumento a partir do funcionamento do Órgão de Solução de Controvérsias da Organização Mundial do Comércio, especificamente o acesso das controvérsias aos Órgãos e os efeitos que suas decisões podem provocar sobre particulares.

\section{Abstract}

Foreign policy formulation has often been overlooked by legal analysts. Nevertheless, the increasing development of International Trade Law has put States in a position in which diplomacy mingles with defending the interest of domestic private parties who benefit from these rules. Accordingly, foreign trade policy should be the outcome of a domestic dialogue between the government and private interested parties: in such a dialogue, legal norms play the pivotal role of allowing better control over foreign policy formulation. The article explores this argument from the perspective of both the access to World Trade Organization's Dispute Settlement Body and the effects its decisions could engender to private parties.

Palavras-chave: Política externa; Direito Internacional do Comércio; Organização Mundial do Comércio; Legalização

Keywords: Foreign policy; International Trade Law; World Trade Organization; Legalization 